\title{
Influence of soil, land use and climatic factors on the hydraulic conductivity of soil
}

\author{
N. Jarvis, J. Koestel, I. Messing, J. Moeys, and A. Lindahl \\ Department of Soil \& Environment, Swedish University of Agricultural Sciences, Box 7014, 75007 Uppsala, Sweden
}

Correspondence to: N. Jarvis (nicholas.jarvis@ @lu.se)

Received: 30 July 2013 - Published in Hydrol. Earth Syst. Sci. Discuss.: 19 August 2013

Revised: 15 November 2013 - Accepted: 23 November 2013 - Published: 20 December 2013

\begin{abstract}
Due to inadequate data support, existing algorithms used to estimate soil hydraulic conductivity, $K$, in (eco)hydrological models ignore the effects of key site factors such as land use and climate and underplay the significant effects of soil structure on water flow at and near saturation. These limitations may introduce serious bias and error into predictions of terrestrial water balances and soil moisture status, and thus plant growth and rates of biogeochemical processes. To resolve these issues, we collated a new global database of hydraulic conductivity measured by tension infiltrometer under field conditions. The results of our analyses on this data set contrast markedly with those of existing algorithms used to estimate $K$. For example, saturated hydraulic conductivity, $K_{\mathrm{s}}$, in the topsoil ( $<0.3 \mathrm{~m}$ depth) was found to be only weakly related to texture. Instead, the data suggests that $K_{\mathrm{S}}$ depends more strongly on bulk density, organic carbon content and land use. In this respect, organic carbon was negatively correlated with $K_{\mathrm{s}}$, presumably due to water repellency, while $K_{\mathrm{s}}$ at arable sites was, on average, ca. 2-3 times smaller than under natural vegetation, forests and perennial agriculture. The data also clearly demonstrates that clay soils have smaller $K$ in the soil matrix and thus a larger contribution of soil macropores to $K$ at and near saturation.
\end{abstract}

\section{Introduction}

Soil hydraulic properties determine water fluxes and storages and thus a range of key biogeochemical processes in the earth's critical zone (NRC, 2001; Lin, 2010). In particular, the hydraulic conductivity of surface soil layers at and near saturation is an important parameter regulating the partitioning of precipitation between surface runoff and ground- water recharge, plant water uptake and plant growth, rates of biogeochemical cycling in soil and risks of pollutant impacts on surface waters and groundwater. Soil hydraulic conductivity is traditionally measured on small samples in the laboratory (Klute and Dirksen, 1986) or with a variety of different infiltrometer techniques in the field (White et al., 1992; Angulo-Jaramillo et al., 2000). These methods are time-consuming, so they are not practical to apply in all cases, especially for larger areas. Thus, for many hydrological model applications, soil hydraulic properties are estimated from more easily available proxy variables such as soil texture, bulk density or organic carbon content. Such estimation approaches are widely referred to as pedotransfer functions (Bouma, 1989; Wösten et al., 2001). Some wellknown examples are the HYPRES functions (Wösten et al., 1999) and ROSETTA (Schaap et al., 2001), which is derived from the global database UNSODA (Nemes et al., 2001). In contrast to soil water retention, these existing approaches often perform poorly for predictions of hydraulic conductivity (Vereecken et al., 2010), especially when the soil is nearly or completely water saturated (e.g. Chirico et al., 2007). One important reason for this is that existing functions are based on measurements made on small cores in the laboratory, which are not representative for hydraulic conductivity in the field, for example, due to inadequate sample size (e.g. Davis et al., 1999) or the disruption of soil macropores during sampling and sample preparation. Thus, existing pedotransfer functions tend to overemphasize the importance of soil texture and underestimate the significant effects of structure (Vereecken et al., 2010). Some efforts have been made to develop improved pedotransfer functions for saturated hydraulic conductivity, $K_{\mathrm{s}}$, that account for soil structure (e.g. McKenzie and Jacquier. 1997; Lin et al., 1999; Lilly et al., 
2008), but these are rarely used, probably because the soil structure descriptors required by these approaches are subjectively assessed and not widely available.

Existing global databases and pedotransfer functions for $K_{\mathrm{S}}$ have several other limitations. For example, they do not address the significant effects of land use and vegetation types on $K_{\mathrm{S}}$ that have been demonstrated in several localand regional-scale studies (e.g. Gonzalez-Sosa et al., 2010; Thompson et al., 2010; Wang et al., 2013). Although few studies have addressed the question, climatic factors might also be expected to affect soil structure and $K_{\mathrm{S}}$ through interactions with vegetation and thus the abundance of root and faunal biopores (Thompson et al., 2010) or physical processes such as freezing and thawing (Hu et al., 2012), water repellency (Wang et al., 2009) and swelling and shrinkage. In a modeling context, errors resulting from the use of parameter estimation routines that ignore these important site controls on saturated hydraulic conductivity may result in significant errors in the partitioning between infiltration/runoff and evaporation/recharge in hydrological models (e.g. Davis et al., 1999; Chirico et al., 2010), soil moisture contents and simulated rates of biogeochemical processes in soils (e.g. nutrient cycling and carbon turnover).

Pedotransfer functions based on field measurements should give more accurate predictions of saturated and near-saturated hydraulic conductivity than laboratory-based methods. In particular, unconfined infiltration measurements made using permeameters that supply water to the soil under a slight tension (so-called tension infiltrometers) reflect the impact of the fragile structural macropores that dominate flow at and close to saturation (Watson and Luxmoore, 1986; Jarvis and Messing, 1995; Jarvis, 2008). The first tension infiltrometer was designed as early as the mid-1970s (Dixon, 1975), but the technique really only became popular following the development of simple methods to estimate hydraulic properties from measured unconfined three-dimensional infiltration rates in the field (Ankeny et al., 1991; Reynolds and Elrick, 1991). There is now a large amount of historical experimental data on hydraulic conductivity measured by tension infiltrometer in the peer-reviewed literature. Surprisingly, no serious attempts have been made to synthesize or analyze this data to derive global pedotransfer functions for saturated and near-saturated hydraulic conductivity. We are aware of only two previous studies of this type, both of which were only of limited scope, based on small data sets (Jarvis et al., 2002; Moosavi and Sepaskhah, 2012).

In this study, we present a global database of measurements made by tension infiltrometer collated from the published peer-reviewed literature. We also present the results of some preliminary statistical analyses carried out on this comprehensive data set to elucidate the influence of soil properties and land use and climatic factors on the near-saturated and saturated hydraulic conductivity of soil.

\section{Methods}

\subsection{Data collection}

Data on hydraulic conductivity, $K$, as a function of water tension, $\psi$, measured by tension infiltrometer was collated from the published literature through ISI Web of Science and Google scholar searches. Data presented in tables were taken directly, while figures were digitized to extract paired $K, \psi$ values. Average values presented for a given plot were recorded in the database, even if data for individual replicates was available. A plot was defined as a measurement location for which all entries in the database for potential predictor variables are identical. Data for a given plot was only entered into the database if the measurements were made on undisturbed soil and for at least 3 paired $K, \psi$ values. A few studies only reported steady-state infiltration rates. In these cases, we calculated hydraulic conductivity from steady-state infiltration using the method of Ankeny et al. (1991), knowing the diameter of the ring. Many studies report hydraulic conductivity at zero tension derived from unconfined infiltration measurements. In our experience, such measurements are liable to error due to leaks from the infiltrometer. This implies that the actual supply potential in these cases must have been slightly negative, since such leakages are quite obvious. For this reason, we assumed a nominal supply tension of $1 \mathrm{~mm}$ whenever hydraulic conductivity data were reported at zero tension.

In total, the database includes 753 individual data sets from 124 different published studies at 144 different locations worldwide (see supplementary material). Comprehensive auxiliary metadata and information on measurement and calculation methods, site characteristics and soil properties was also entered into the database (see Tables 1 and 2), which can also be obtained on request from the corresponding author. Among the studies included in the database, climate data for the measurement sites was only infrequently reported. Thus, we estimated climate variables at each location using the FAO New LocClim model (http://www.fao. org/nr/climpag/pub/en3_051002_en.asp), which uses inverse distance weighting to spatially interpolate measured longterm meteorological data records for a global network of sites. In some of the studies included in the database, annual average precipitation was also reported (see Table 2), and this data was used to successfully validate the New LocClim estimates (see Supplement).

\subsection{Summarizing the hydraulic conductivity data}

The number and magnitude of supply tensions at which infiltration was measured varied widely between studies and sometimes also within studies. We therefore summarized each data set by fitting a simple model of near-saturated 
Table 1. Class variables recorded in the database.

\begin{tabular}{|c|c|c|}
\hline Group & Variable & Number in each class \\
\hline \multicolumn{3}{|c|}{ Land use } \\
\hline & Arable & 471 \\
\hline & Rotational (e.g. including ley/fallow) & 62 \\
\hline & Perennial agriculture (e.g. managed grassland, orchards) & 91 \\
\hline & Forests & 33 \\
\hline & Natural grassland/bush/tundra/savannna & 66 \\
\hline & Other & 20 \\
\hline & Total & 743 \\
\hline \multicolumn{3}{|l|}{ Tillage } \\
\hline & If land use $=$ arable or rotational & \\
\hline & Conventional & 250 \\
\hline & Reduced/minimum/conservation & 70 \\
\hline & No-till & 82 \\
\hline & Total & 402 \\
\hline \multicolumn{3}{|c|}{ Texture class ${ }^{\mathrm{a}}$} \\
\hline & Coarse & 41 \\
\hline & Medium & 279 \\
\hline & Medium-fine & 209 \\
\hline & Fine & 208 \\
\hline & Organic & 2 \\
\hline & Total & 739 \\
\hline \multicolumn{3}{|c|}{ Methods } \\
\hline & Estimation of conductivity from infiltration & \\
\hline & 1-D confined (columns, rings) $)^{b}$ & 102 \\
\hline & Steady-state, multiple tensions, single log-linear ${ }^{\mathrm{c}}$ & 77 \\
\hline & Steady-state, multiple tensions, piece-wise log-linear ${ }^{\mathrm{d}}$ & 506 \\
\hline & Steady-state, multiple disc radii ${ }^{\mathrm{e}}$ & 9 \\
\hline & Transient $\mathrm{f}^{\mathrm{f}}$ & 46 \\
\hline & Other methods & 13 \\
\hline & Total & 753 \\
\hline & Sequence of supply tensions & \\
\hline & Dry to wet & 386 \\
\hline & Wet to dry & 105 \\
\hline & Total & 491 \\
\hline & Month of measurement (first, last) & \\
\hline & Total & 616 \\
\hline
\end{tabular}

a based on the USDA system: coarse is sand or loamy sand; medium is sandy loam, loam, sandy clay loam or sandy clay; medium-fine is silt loam or silt; fine is clay, silty clay, silty clay loam or clay loam. ${ }^{b}$ confined infiltration: steady-state flow rate is assumed equal to hydraulic conductivity. ${ }^{c}$ following Logsdon and Jaynes (1993). ${ }^{\mathrm{d}}$ following, for example, Reynolds and Elrick (1991) or Ankeny et al. (1991). ${ }^{\mathrm{e}}$ following Smettem and Clothier (1989). ${ }^{\mathrm{f}}$ methods requiring early time transient infiltration measurements e.g., Vandervaere et al. (2000).

hydraulic conductivity to the reported data (Jarvis, 2008):

$\frac{K(\psi)}{K_{\mathrm{s}}}=\left(\frac{\psi_{\min }}{\psi}\right)^{n^{*}}, \quad \psi \geq \psi_{\min }$,

$K(\psi)=K_{\mathrm{s}}, \quad \psi<\psi_{\min }$,

where $K_{\mathrm{S}}$ is the saturated hydraulic conductivity, $\psi_{\min }$ is the water/air-entry tension corresponding to the largest pore in the soil and $n^{*}$, which reflects macropore size distribution and tortuosity (Jarvis, 2008), is given by the slope of $K(\psi)$ on a plot of $\log K$ vs. $\log \psi$. It should be noted that $\psi_{\text {min }}$ (and therefore $K_{\mathrm{s}}$ ) could not be defined for many data sets, since measurements were not made at supply tensions close enough to saturation (see Fig. 1 for an example). For this reason, fitted values of $n^{*}$ and, where possible, $\psi_{\min }$ were stored in the database together with $K$ estimated at $\psi=10 \mathrm{~cm}$, the $R^{2}$ value of the fit and the minimum and maximum supply tensions (see Table 2). From this data, $K$ can be estimated at 
Table 2. Continuous variables recorded in the database, with some descriptive statistics.

\begin{tabular}{|c|c|c|c|}
\hline Group & Variable and units & $\begin{array}{r}\text { Number of } \\
\text { entries }\end{array}$ & Descriptive statistics ${ }^{\mathrm{a}}$ \\
\hline \multicolumn{4}{|c|}{ Soil properties } \\
\hline & Clay content, $f_{\text {clay }}\left(\mathrm{kg} \mathrm{kg}^{-1}\right)$ & 616 & $(0.003,0.19,0.80), 0.14$ \\
\hline & Silt content ${ }^{\mathrm{b}}\left(\mathrm{kg} \mathrm{kg}^{-1}\right)$ & 530 & $(0.008,0.40,0.78), 0.20$ \\
\hline & Sand content ${ }^{\mathrm{b}}\left(\mathrm{kg} \mathrm{kg}^{-1}\right)$ & 528 & $(0.01,0.29,0.97), 0.23$ \\
\hline & Bulk density, $\gamma\left(\mathrm{g} \mathrm{cm}^{-3}\right)$ & 376 & $(0.60,1.32,1.90), 0.22$ \\
\hline & Organic carbon content, $f_{\mathrm{oc}}\left(\mathrm{kg} \mathrm{kg}^{-1}\right)$ & 469 & $(0.0007,0.014,0.167), 0.021$ \\
\hline \multicolumn{4}{|c|}{$\begin{array}{l}\text { Site location } \\
\text { and climate }\end{array}$} \\
\hline & Latitude, longitude (degrees) & 144 & \multirow{6}{*}{$\begin{array}{r}(130,638,3692), 376 \\
(0.6,11.3,29.0), 4.8\end{array}$} \\
\hline & Annual precipitation (reported by authors; $\mathrm{mm}$ ) & 55 & \\
\hline & Estimated annual precipitation ${ }^{\mathrm{c}}, P_{\mathrm{est}}(\mathrm{mm})$ & 144 & \\
\hline & Estimated mean annual temperature ${ }^{\mathrm{c}}, T_{\text {est }}\left({ }^{\circ} \mathrm{C}\right)$ & 144 & \\
\hline & Estimated annual potential evapotranspiration ${ }^{\mathrm{c}}(\mathrm{mm})$ & 144 & \\
\hline & Potential net primary productivity ${ }^{\mathrm{c}}\left(\mathrm{g} \mathrm{DM} \mathrm{m}^{-2} \mathrm{yr}^{-1}\right)$ & 144 & \\
\hline \multicolumn{4}{|c|}{ Methods } \\
\hline & Depth of measurement (m) & 753 & $(0,0,4.0), 0.19$ \\
\hline & Minimum and maximum supply tensions (mm) & 753 & $(0,0,50), 10.4(20,105,240), 44.3$ \\
\hline & Diameter of infiltrometer $(\mathrm{cm})$ & 578 & $(4,17.3,28), 6.2$ \\
\hline \multicolumn{4}{|c|}{$\begin{array}{l}\text { Target variables and } \\
\text { model fit }\end{array}$} \\
\hline & Hydraulic conductivity at $10 \mathrm{~cm}$ tension ${ }^{\mathrm{d}}, K_{10}\left(\mathrm{~mm} \mathrm{~h}^{-1}\right)$ & 753 & \multirow{5}{*}{$\begin{array}{r}(-2.0,0.415,2.26), 0.61^{e} \\
(0.51,1.87,4.78), 0.59^{f}\end{array}$} \\
\hline & Hydraulic conductivity at saturation, $K_{\mathrm{S}}\left(\mathrm{mm} \mathrm{h}^{-1}\right)$ & 753 & \\
\hline & Slope of the $K(\psi)$ function ${ }^{\mathrm{d}, \mathrm{g}}(-)$ & 753 & \\
\hline & Tension equivalent to largest pore in soil ${ }^{\mathrm{d}, \mathrm{h}}$ & 528 & \\
\hline & $R^{2}$ value of model fit & 753 & \\
\hline
\end{tabular}

\footnotetext{
a minimum, median and maximum values in parentheses, standard deviation outside parentheses. ${ }^{\mathrm{b}}$ standardized, where necessary, to the USDA system, using log-linear interpolation. ${ }^{\mathrm{c}}$ estimated using FAO New LocClim. ${ }^{\mathrm{d}}$ estimated by fitting to Jarvis (2008). ${ }^{\mathrm{e}} \log _{10}\left(K_{10}\right)$ for data entries with maximum supply tension $\geq 80 \mathrm{~mm}(n=537){ }^{\mathrm{f}} \log _{10}\left(K_{\mathrm{S}}\right)$ for data entries with minimum supply tension $\leq 5 \mathrm{~mm}(n=470) .{ }^{\mathrm{g}}=n^{*}$ in Eq. $(1) .{ }^{\mathrm{h}}=\psi_{\mathrm{min}}$ in Eq. $(1)$.
}

any tension for each data set. Eq. (1) gave $R^{2}$ values larger than 0.9 for ca. $90 \%$ of the individual data sets (Fig. 2).

\subsection{Multivariate regression}

Multivariate ordinary least-squares regression (MLR) models were developed for hydraulic conductivity at saturation, $K_{\mathrm{s}}$, and $10 \mathrm{~cm}$ tension, $K_{10}$, and for the contribution of macropores to $K_{\mathrm{S}}\left(=K_{\mathrm{s}}-K_{10}\right.$, hereafter termed $\left.K_{\mathrm{s}(\mathrm{ma})}\right)$ using a "bootstrapping" procedure (re-sampling with replacement) in which $63 \%$ (on average) of the data points are used to build equations, while $37 \%$ (on average) are not sampled and thus retained for validation. The bootstrapping procedure was repeated 250 times to ensure stable results. MLR cannot easily deal with categorical variables, and especially with hierarchical dependencies among them (i.e. land use and tillage systems, see Table 1). However, land use was included as a potential predictor variable by defining binary variables $(1=$ yes, $0=$ no) for three broader land use classes that reflect traffic and cultivation intensity: arable or rotational agri- culture (LUT2), perennial agriculture (LUT1), and forests or natural vegetation (LUT0). In order to minimize problems due to correlations among predictors, we included only six continuous variables (depth of measurement, clay content, bulk density, organic carbon content, annual precipitation, average annual temperature) in the analysis. Nevertheless, some of these predictors were still significantly correlated, so in addition to ordinary MLR, we also tested ridge-regression, which accounts for such correlations. However, the results of both methods were very similar, so we only present the results of ordinary MLR. Ordinary MLR models containing all possible combinations of these predictor variables were tested (i.e. a best subset regression for 255 possible models). For each dependent variable, the best model was selected as the one with the smallest value of the Akaike information criterion, an approach that penalizes overfitting. Model performance was also assessed with validation root mean square errors of prediction (RMSEP) and validation $R^{2}$ values calculated on the 250 sets of bootstrap samples. 


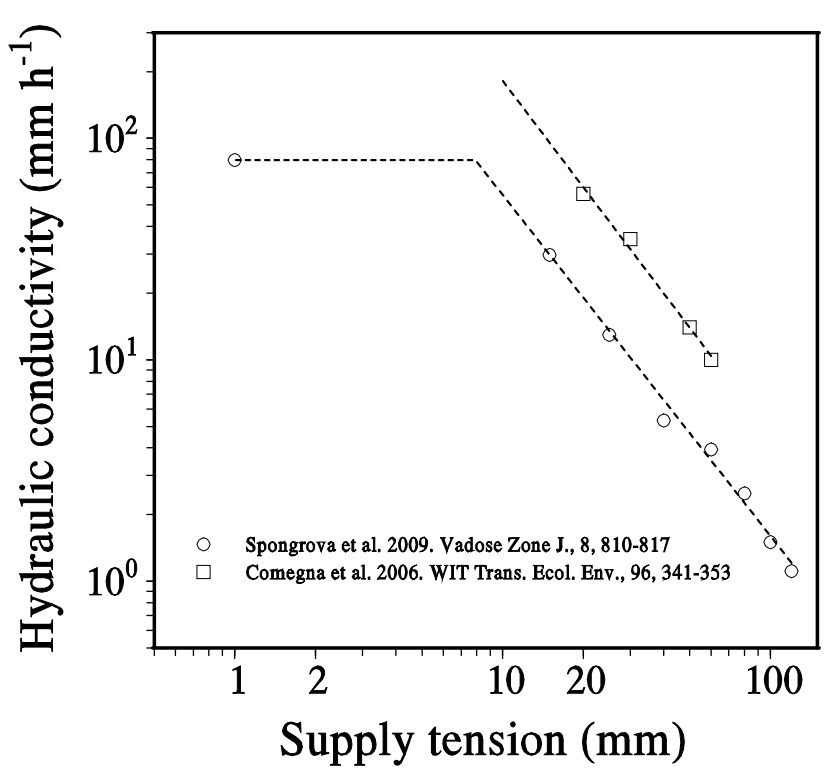

Fig. 1. Example fits of Eq. (1) to the data.

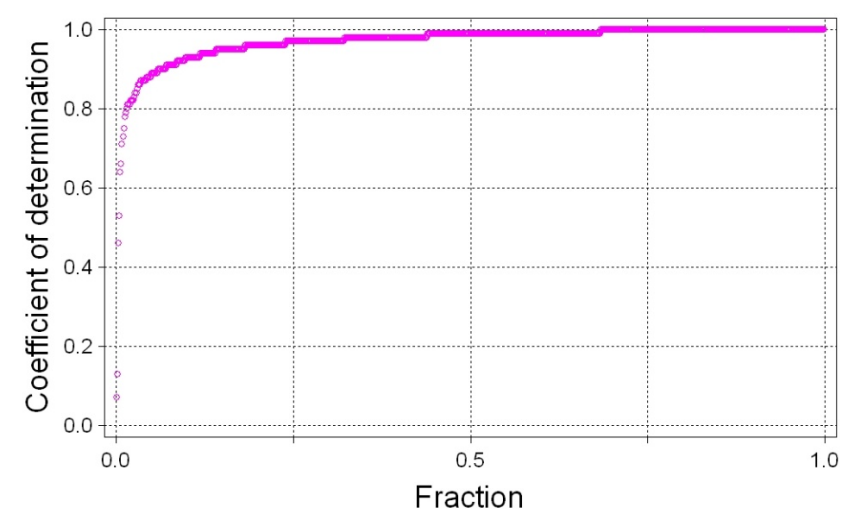

Fig. 2. The distribution of $R^{2}$ values for fits of Eq. (1) to the data sets in the database.

We excluded two organic soils from the MLR analysis, since as extreme outliers these could have biased regressions that use organic carbon content as a predictor. We also excluded measurements made in the subsoil (i.e. where the infiltrometer was placed at depths $>0.3 \mathrm{~m}$ ), since we assumed that the influence of land use and climate would be stronger in topsoil than in subsoil. Ideally, we would have liked to develop separate regression equations for subsoil data, but the number of data points was too small: only 32 entries in the database refer to measurements carried out at depths $>0.3 \mathrm{~m}$. We also excluded records for which extrapolation too far beyond the range of measured data was needed to estimate hydraulic conductivity from the model fits (see Table 3). We also investigated whether better MLR models could be obtained by excluding data sets for which Eq. (1) fitted poorly. However, no clear improvements were
Table 3. Criteria for data inclusion in the multivariate regression analysis.

\begin{tabular}{ll}
\hline Target variable & Criteria \\
\hline$K_{\mathrm{S}}$ & $\begin{array}{l}\text { Mineral soil (Texture class } \neq \text { Organic) } \\
\text { Topsoil (Measurement depth } \leq 0.3 \mathrm{~m} \text { ) } \\
\end{array}$ \\
\hline$K_{10}$ & Minimum supply tension $\leq 0.5 \mathrm{~cm}$ \\
& Mineral soil (Texture class $\neq$ Organic) \\
& Topsoil (Measurement depth $\leq 0.3 \mathrm{~m}$ ) \\
& Maximum supply tension $\geq 8 \mathrm{~cm}$ \\
& Method of $K$ estimation: 3 -D unconfined \\
& (from steady-state infiltration, assuming \\
& $K(\psi)$ is piecewise log-linear), dry-to-wet \\
& sequence of supply tensions \\
\hline$K_{\mathrm{S}(\mathrm{ma})}$ & Mineral soil (Texture class $\neq$ Organic) \\
& Topsoil (Measurement depth $\leq 0.3 \mathrm{~m}$ ) \\
& Minimum supply tension $\leq 0.5 \mathrm{~cm}$ \\
& Maximum supply tension $\geq 8 \mathrm{~cm}$ \\
\hline &
\end{tabular}

obtained for a range of cutoff $R^{2}$ values tested, and so no such limitation was imposed.

\section{Results and discussion}

Table 1 shows that, in contrast to UNSODA, medium- and fine-textured soils are very well represented in the database. As noted above, this is because tension infiltrometry has been widely applied to study the effects of soil structure on hydraulic conductivity. Table 1 also shows that ca. $72 \%$ of the data entries are from arable/rotational sites, $15 \%$ from managed permanent grassland or perennial agriculture (e.g. orchards), while the remaining data (ca. 13\%) comes from forests or natural vegetation. Table 4 illustrates the relationship between soil texture and three broad land use types, which represent different degrees of cultivation and traffic intensity. Applying Pearson's chi-squared test to the joint frequency distribution shown in Table 4 suggests that it is not homogeneous and that a significant interaction exists between the two variables. Most of this is due to the predominance of natural vegetation and forest sites on coarsetextured soils: this combination of land use and soil texture class represents more than half of the total chi-squared value (Table 4).

Figure 3 shows the relationships between two of the target variables, the saturated hydraulic conductivity, $K_{\mathrm{s}}$, and the saturated hydraulic conductivity of the soil matrix (defined as $K$ at a tension of $10 \mathrm{~cm}$ ), $K_{10}$, and several potential predictor variables. The plots for hydraulic conductivity in Fig. 3 show that $K_{\mathrm{s}}$ is typically 1 to 3 orders of magnitude larger than $K_{10}$ due to the effects of soil macropores (e.g. shrinkage cracks, tillage voids, bio-pores) on $K$ near saturation. In comparison, $K$ decreases, on average, by a little less than 1 order of magnitude close to saturation for the soils in the UNSODA database (Schaap and Leij, 2000), which contains 
Table 4. Contingency table for soil texture and land use classes (mineral topsoils only). The overall chi-squared statistic is 83.2 , with $p<0.0001)$.

\begin{tabular}{llrrrrr}
\hline \multirow{2}{*}{ Land use $^{1}$} & & \multicolumn{2}{c}{ Texture class $^{2}$} & & & \\
\cline { 3 - 7 } & & Coarse & Medium & Medium-fine & Fine & Total \\
\hline \multirow{2}{*}{ LUT0 } & Observed & 22 & 32 & 22 & 20 & 96 \\
& Expected & 5.2 & 36.4 & 29.2 & 25.2 & \\
& Cell chi-squared & 54.59 & 0.54 & 1.78 & 1.07 & \\
\hline \multirow{2}{*}{ LUT1 } & Observed & 0 & 41 & 12 & 16 & 69 \\
& Expected & 3.7 & 26.2 & 21.0 & 18.1 & \\
& Cell chi-squared & 3.72 & 8.40 & 3.86 & 0.24 & \\
\hline \multirow{2}{*}{ LUT2 } & Observed & 14 & 180 & 169 & 139 & 502 \\
& Expected & 27.1 & 190.4 & 152.8 & 131.7 & \\
& Cell chi-squared & 6.33 & 0.57 & 1.72 & 0.40 & \\
\hline Total & & 36 & 253 & 203 & 175 & 667 \\
\hline${ }^{1}$ LUT0 represents natural vegetation or forest, LUT1 represents perennial agriculture, LUT2 represents arable or \\
rotational agriculture. ${ }^{2}$ see Table 1 for explanations. & & & &
\end{tabular}

Table 5. Results of analysis of variance for $\log K_{10}$ : pair-wise comparison of means for $K$ estimation methods.

\begin{tabular}{lr}
\hline Method & $\begin{array}{r}\text { Mean } \log K_{10}{ }^{*} \\
\left(\mathrm{~mm} \mathrm{~h}^{-1}\right)\end{array}$ \\
\hline $\begin{array}{l}\text { Steady-state, multiple tensions, } \\
\text { single log-linear }\end{array}$ & $0.831^{\mathrm{a}}$ \\
Other methods & $0.827^{\mathrm{a}}$ \\
1D confined (columns, rings) & $0.686^{\mathrm{a}}$ \\
Steady-state, multiple disc radii & $0.660^{\mathrm{a}, \mathrm{b}}$ \\
Steady-state, multiple tensions, & $0.317^{\mathrm{b}, \mathrm{c}}$ \\
piece-wise log-linear & $0.273^{\mathrm{c}}$ \\
Transient & \\
\hline * Means with same letter are not significantly different at $p=0.05$.
\end{tabular}

more coarse-textured soils. As has previously been found for smaller regional-scale data sets (Børgesen et al., 2006), the largest macropore hydraulic conductivities $\left(=K_{\mathrm{s}}-K_{10}\right)$ are generally found for finer-textured soils of smaller matrix hydraulic conductivity. Furthermore, contrary to the predictions of widely used estimation algorithms, Fig. 3 suggests that there is no clear trend of $K_{\mathrm{S}}$ with soil texture. Thus, on average, $K_{\mathrm{s}}$ in clayey-textured soils is just as large as in non-structured sands, due to the contribution of macropores. One important caveat here is that more than $90 \%$ of the measurements in the database were made in the topsoil $(<0.3 \mathrm{~m}$ depth), due to the practical difficulties of applying this technique in subsoil. Although we cannot test the hypothesis here, it seems likely that textural controls on $K_{\mathrm{S}}$ should become more dominant in deeper subsoil, where the effects of structure-forming biological and physical processes are weaker. Figure 3 also illustrates the extent of correlations between potential predictor variables of hydraulic
Table 6. Results of analysis of variance for $\log K_{10}$ : pair-wise comparison of means for supply tension sequence.

\begin{tabular}{lr}
\hline Method & $\begin{array}{r}\text { Mean } \log K_{10}{ }^{*} \\
\left(\mathrm{~mm} \mathrm{~h}^{-1}\right)\end{array}$ \\
\hline Wet-to-dry & $0.736^{\mathrm{a}}$ \\
Unknown/unspecified & $0.698^{\mathrm{a}}$ \\
Dry-to-wet & $0.471^{\mathrm{b}}$ \\
\hline * Means with same letter are not significantly different \\
at $p=0.05$.
\end{tabular}

conductivity. For example, coarse-textured soils tend to have somewhat larger bulk densities and smaller organic carbon contents. Organic carbon content also tends to be larger in soils under natural vegetation, while bulk density shows no apparent trend with land use. The two climate variables in the database show no significant correlation with soil properties, with the exception of annual average air temperature, which is weakly and positively correlated with clay content.

In the absence of confining rings or cores, unconfined three-dimensional infiltration occurs from the base plate of the infiltrometer and the measured infiltration rates must therefore be converted to an estimate of (one-dimensional) hydraulic conductivity. Several methods have been proposed, but Table 1 shows that those based on steady-state infiltration and a piece-wise log-linear approximation to $K(\psi)$ (Reynolds and Elrick, 1991; Ankeny et al. 1991) are by far the most popular. Measurements of $K(\psi)$ can also be made either in an ascending or descending sequence of water tensions. Table 1 shows that a descending sequence of tensions (i.e. from dry to wet) predominates. It is well known from local-scale studies that the various methods used to estimate hydraulic conductivity from measured infiltration rates can 
Table 7. Multivariate ordinary linear regression models ( $f_{\mathrm{oc}}$ is soil organic carbon content, $\mathrm{kg} \mathrm{kg}^{-1} ; f_{\text {clay }}$ is the soil clay content $\mathrm{kg}$ kg ${ }^{-1}$; $\gamma$ is the soil bulk density, $\mathrm{g} \mathrm{cm}^{-3} ; T_{\text {est }}$ is the annual average air temperature, ${ }^{\circ} \mathrm{C}$; LUT2 $=1$ if land use is arable or rotational).

\begin{tabular}{|c|c|c|c|c|c|c|c|c|}
\hline $\begin{array}{l}\text { Target } \\
\text { variable }\end{array}$ & $N$ & Intercept & Predictors & Coefficients & RMSEP $^{\mathrm{a}}$ & $\begin{array}{r}\text { Validation } \\
\qquad R^{2}\end{array}$ & RMSEC $^{\mathrm{b}}$ & $\begin{array}{r}\text { Calibration } \\
R^{2}\end{array}$ \\
\hline $\log K_{\mathrm{S}} \mathrm{c}$ & 220 & 3.796 & $f_{\mathrm{oc}}, \gamma, \mathrm{LUT} 2$ & $-5.083,-1.152,-0.454$ & $0.559(0.544)$ & 0.19 & 0.539 & 0.25 \\
\hline $\log K_{10} \mathrm{~d}$ & 119 & 0.481 & $f_{\text {clay }}, \gamma, T_{\text {est }}$ & $-1.883,-0.823,0.105$ & $0.411(0.398)$ & 0.32 & 0.396 & 0.41 \\
\hline $\log K_{\mathrm{s}(\mathrm{ma})}{ }^{e}$ & 220 & 3.206 & $f_{\text {clay }}, \gamma$, LUT2 & $1.736,-1.100,-0.372$ & $0.568(0.567)$ & 0.21 & 0.565 & 0.27 \\
\hline
\end{tabular}

a RMSEP is the validation root mean square error of prediction. Figures in parentheses are the minimum RMSEP's of all 255 models that were tested. ${ }^{\mathrm{b}}$ RMSEC is the root

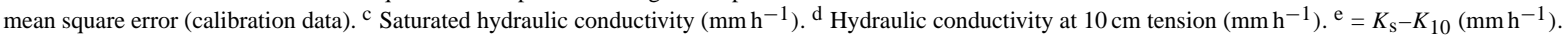

give significantly different results (Jacques et al., 2002; Ventrella et al., 2005), as can the direction of the sequence of infiltration runs (e.g. Clothier and Smettem, 1990; Bagarello et al., 2007). We therefore performed an analysis of variance for $\log K_{\mathrm{s}}, \log K_{\mathrm{s}(\mathrm{ma})}$ and $\log K_{10}$ for these two factors to check whether such effects were apparent in the database. No significant effects of measurement method or hysteresis were detected for $\log K_{\mathrm{S}}$ or $\log K_{\mathrm{s}(\mathrm{ma})}$, but both factors were highly significant for $\log K_{10}$ (see Tables 5 and 6). To check whether this result was affected by correlations with soil factors, we applied a chi-squared test to contingency tables of experimental methods against soil texture class. This analysis showed some significant bias with texture for the lesser-used methods of $K$ determination, perhaps arising by chance due to small sample sizes, but none (with $97.3 \%$ confidence) for the two dominant methods in the database (see Table 1). Of these two methods, $K_{10}$ was largest for the least-squares regression method proposed by Logsdon and Jaynes (1993), which assumes a log-linear, near-saturated $K(\psi)$ function of constant slope (see Table 5 ). As noted by Logsdon and Jaynes (1993), this method may perform poorly if it is applied across a wide range of tensions in strongly structured soils, where the slope of $\log K$ vs. $\psi$ often decreases markedly across the tension range close to saturation (Jarvis and Messing, 1995). This limitation may not have been widely appreciated and understood, which may be why $K_{10}$ values were largest for this method. The analysis also indicated hysteresis effects, with larger $K_{10}$ values, on average, for drainage (i.e. wet-to-dry) sequences (Table 6). Thus, as a result of this analysis, a more restricted data set was used to develop MLR models for $\log K_{10}$, consisting of data obtained from steady-state unconfined (i.e. 3-D) infiltration tests measured for a dry-to-wet sequence of supply tensions and assuming a piece-wise log-linear approximation to $K(\psi)$ (Table 3).

Table 7 shows selected bootstrapped multivariate ordinary least-squares regression (MLR) models for $K_{\mathrm{s}}, K_{10}$ and $K_{\mathrm{S}(\mathrm{ma})}\left(=K_{\mathrm{s}}-K_{10}\right)$. Figure $4 \mathrm{a}-\mathrm{d}$ illustrates the performance of the model for $K_{\mathrm{s}}$. Corresponding plots for $K_{10}$ and $K_{\mathrm{s}(\mathrm{ma})}$ are presented in the supplementary material. The use of the Akaike information criterion favored the selection of relatively parsimonious models with only three predictor vari- ables (Table 7). It can be noted that the validation root mean square error of prediction for these models was only $1-3 \%$ larger than for the best-fit models, which contained more predictors (Table 7). The predictive power of the selected models is relatively modest, with validation $R^{2}$ values from 0.19 to 0.32 and RMSEP values for $\log K$ ranging from 0.41 to 0.57 (Table 7). These performance statistics are slightly better for the calibration data (Table 7), and also compare favorably to the performance of existing estimation algorithms (Vereecken et al., 2010). Indeed, better accuracy can almost certainly not be expected, because (i) the measurements in a global database like this may be influenced by unknown differences in experimental conditions and procedures (Reynolds, 2006), (ii) it seems highly likely that there are many complex non-linear and/or hierarchical dependencies between variables in the data set that simple linear, additive, models cannot capture, and (iii) $K$ at and close to saturation depends on the geometry and topology of a few larger soil pores, which may not be strongly correlated with properties of the bulk soil (Ghafoor et al., 2013). This is also the reason for the large and apparently random short-range spatial variation in $K_{\mathrm{S}}$ frequently found in field, hillslope and catchment-scale studies (Mallants et al., 1996; Buttle and House, 1997; Shouse and Mohanty 1998).

Bulk density, land use and soil organic carbon content were identified as the three most important predictors for $K_{\mathrm{S}}$ (see Table 7 and Fig. 4b). Organic carbon is usually considered to improve soil structure, which would imply a positive correlation with $K_{\mathrm{s}}$. However, Table 7 suggests the opposite, with $K_{\mathrm{S}}$ apparently decreasing as organic carbon content increases. This trend, which may be due to sub-critical soil water repellency, is also apparent in other global databases and pedotransfer functions for $K_{\mathrm{S}}$ (Nemes et al., 2005). Negative correlations between $K_{\mathrm{s}}$ and soil organic carbon have also been found in some local- and regional-scale studies (e.g. Wang et al., 2009, 2013). Table 7 shows that intensive cultivation of arable land apparently reduces topsoil $K_{\mathrm{S}}$ by, on average, a factor of ca. 2-3 compared with perennial agriculture, natural vegetation and forests. It seems probable that this may be mostly attributed to the effects of tillage, which disrupts the continuity of macropores, especially faunal and root biopores (Jarvis, 2007). The results of this global 


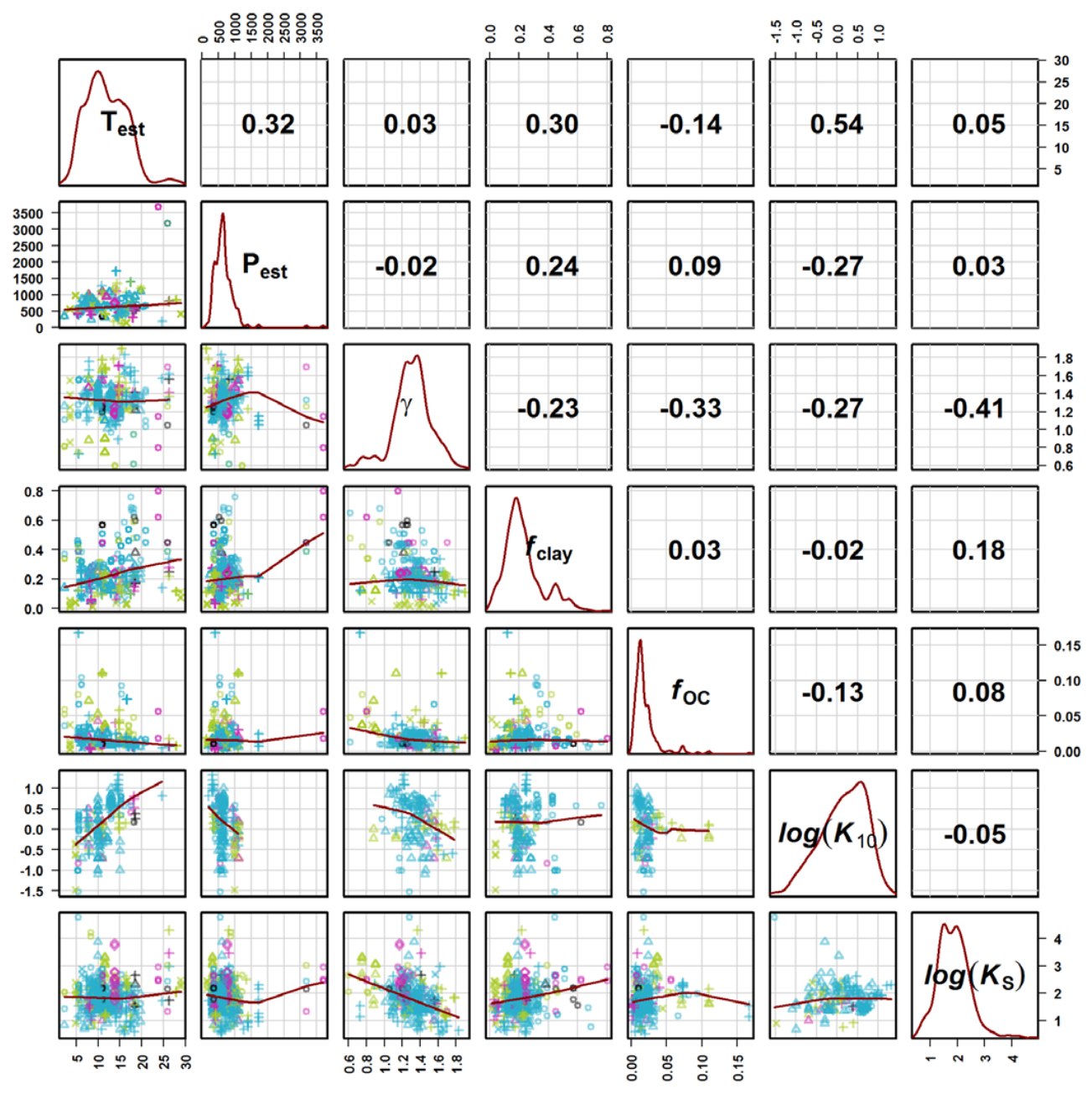

Fig. 3. Scatter-plot matrix showing relationships between variables in the database. The symbols represent texture classes (angled cross for coarse, cross for medium, triangle for medium-fine, open circle for fine, square for unknown; see also Table 1), while the colors represent land use classes (olive green is LUT0, natural vegetation or forests; purple is LUT1, perennial agriculture; sky blue is LUT2, arable or rotational agriculture; black is unknown land use; see also Table 1). The thin red lines represent non-linear regression (locally weighted least-squares regression, LOESS) fits to the measured data. The figures in the main diagonal show a kernel density estimate for the variable (an estimate of the probability density function). Pearson correlation coefficients are shown in the panes to the right of the main diagonal. $T_{\mathrm{est}}$ is in ${ }^{\circ} \mathrm{C}$, $P_{\text {est }}$ in $\mathrm{mm} \mathrm{yr}^{-1}, \gamma$ in $\mathrm{g} \mathrm{cm}^{-3}, f_{\text {clay }}$ and $f_{\mathrm{oc}}$ in $\mathrm{kg} \mathrm{kg}^{-1}$, and $\log _{10}\left(K_{10}\right)$ and $\log _{10}\left(K_{\mathrm{S}}\right)$ in $\log _{10}\left(\mathrm{~mm} \mathrm{~h}^{-1}\right)$.

analysis are supported by several local- and regional-scale studies, which show reduced near-saturated and saturated hydraulic conductivity in cultivated soil compared with soil under natural vegetation (e.g. Bridge and Bell, 1994; Whitbread et al., 2000; Fuentes et al., 2004; Zhou et al., 2008; Wang et al., 2013). A significant effect of bulk density on $K_{\mathrm{S}}$ was also detected (Table 7, Fig. 4b). In our study, this is probably mostly related to the effects of temporal variations in porosity in cultivated arable topsoil due to cycles of tillage and subsequent consolidation, although bulk density may also affect $K_{\mathrm{S}}$ under natural vegetation (e.g. Hu et al., 2012).

Unsaturated hydraulic conductivity is difficult and timeconsuming to measure and so is commonly estimated from measured or predicted $K_{\mathrm{S}}$ values using capillary bundle mod- els of the soil pore system (Van Genuchten, 1980). Using $K_{\mathrm{S}}$ as a "matching point" in approaches based on these unimodal models of soil hydraulic functions can lead to serious overestimation of unsaturated hydraulic conductivity, since they ignore the effects of soil macropores (Schaap and Leij, 2000; Jarvis et al., 2002). More reliable estimates of unsaturated $K$ can be obtained with the matching point hydraulic conductivity set at a tension where macropores no longer conduct water. Here, this tension is assumed to be $10 \mathrm{~cm}$ (Jarvis, 2007). Table 7 shows that in contrast to $K_{\mathrm{s}}$, clay content exerts a significant control on the saturated matrix hydraulic conductivity, $K_{10}$, with smaller values found in finetextured soils. $K_{10}$ is also negatively correlated with bulk density, with a regression coefficient only slightly smaller 

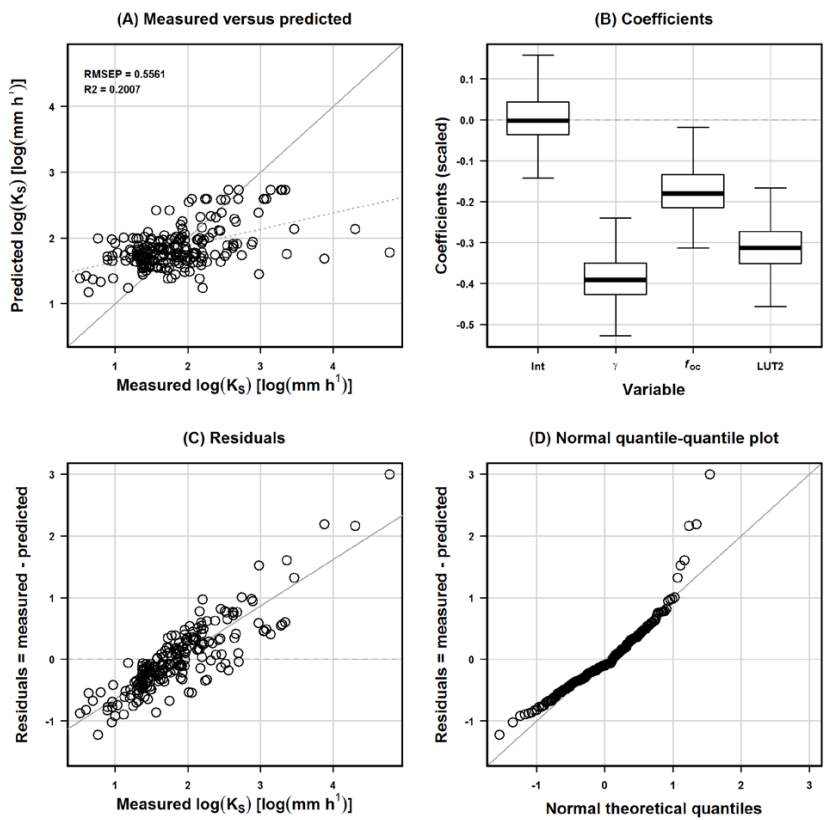

Fig. 4. (A) Measured vs. predicted $K_{\mathrm{S}}$ values, (B) box-and-whisker plots of the bootstrapped normalized model coefficients (for unscaled coefficients, see Table 7), (C) residuals as a function of measured $K_{\mathrm{S}}$, and (D) a quantile plot showing how well the residuals match a normal distribution.

than for $K_{\mathrm{s}}$, which suggests that compaction and loosening affects $K$ similarly across the entire near-saturated tension range. Interestingly, the annual average temperature at the site, $T_{\mathrm{est}}$, was found to be positively correlated to $K_{10}$ (Table 7). The reasons for this are not clear, but one possible explanation is the greater risk of soil compaction in cold climates with short growing seasons, where farmers are often obliged to cultivate and traffic arable topsoil despite unfavorable soil conditions. Finally, the model for macropore hydraulic conductivity, $K_{\mathrm{S}(\mathrm{ma})}$, suggests a positive correlation with clay content and negative correlations with bulk density and arable land use (Table 7).

\section{Conclusions}

The results of the bootstrapped MLR should be considered as illustrative of the main factors controlling saturated and nearsaturated hydraulic conductivity in soil, but the relatively modest values obtained for the validation statistics suggests that caution should be exercised in their predictive use. In this respect, it seems likely that the application of advanced "machine learning" techniques (e.g. classification and regression trees, random forests, neural networks), which can account for the complex non-linear and hierarchical relationships that unquestionably exist among many of the key predictor variables will yield more powerful predictive tools. Further research in this direction is in progress. We also intend to up- date the database as new data becomes available. In this respect, additional measurements made in subsoil and in nonarable land would be most valuable.

Nevertheless, the global explanatory analysis of the factors controlling saturated and near-saturated hydraulic conductivity presented here gives results that contrast strikingly with existing pedotransfer functions, in that our study highlights the dominant role played by soil structure. This can be attributed to the different data support in our study, which consists of field measurements made in topsoil rather than laboratory data. In particular, we demonstrated effects of both land use and climate on $K$. Arable sites have, on average, ca. 2-3 times smaller $K_{\mathrm{s}}$ values than natural vegetation, forests and perennial agriculture. Furthermore, although $K_{\mathrm{s}}$ was only weakly correlated with soil texture, $K$ measured at a supply tension of $10 \mathrm{~cm}$ was significantly and inversely correlated with clay content. Thus, clayey soils have smaller $K$ in the soil matrix and a larger contribution of soil macropores to $K$ at and near saturation.

\section{Supplementary material related to this article is available online at http://www.hydrol-earth-syst-sci.net/ 17/5185/2013/hess-17-5185-2013-supplement.pdf.}

Edited by: N. Ursino

\section{References}

Angulo-Jaramillo, R., Vandervaere, J.-P., Roulier, S., Thony, J.-L., Gaudet, J.-P., and Vauclin, M.: Field measurement of soil surface hydraulic properties. A review and recent developments, Soil Till. Res., 55, 1-29, 2000.

Ankeny, M. D., Ahmed, M., Kaspar, T. C., and Horton, R.: Simple field method for determining unsaturated hydraulic conductivity, Soil Sci. Soc. Am. J., 55, 467-470, 1991.

Bagarello, V., Castellini, M., and Iovino, M.: Comparison of unconfined and confined unsaturated hydraulic conductivity, Geoderma, 137, 394-400, 2007.

Børgesen, C. D., Jacobsen, O. H., Hansen, S., and Schaap, M. G.: Soil hydraulic properties near saturation, an improved conductivity model, J. Hydrol., 324, 40-50, 2006.

Bouma, J.: Using soil survey data for quantitative land evaluation, Adv. Soil Sci. 9, 177-213, 1989.

Bridge, B. J. and Bell, M. J.: Effect of cropping on the physical fertility of Krasnozems, Aust. J. Soil Res., 32, 1253-1273, 1994.

Buttle, J. M. and House, D. A.: Spatial variability of saturated hydraulic conductivity in shallow macroporous soils in a forested basin, J. Hydrol., 203, 127-142, 1997.

Chirico, G. B., Medina, H., and Romano, N.: Uncertainty in predicting soil hydraulic properties at the hillslope scale with indirect methods, J. Hydrol., 334, 405-422, 2007.

Chirico, G. B., Medina, H., and Romano, N.: Functional evaluation of PTF prediction uncertainty: an application at hillslope scale, Geoderma, 155, 193-202, 2010.

Clothier, B. E. and Smettem, K. R. J.: Combining laboratory and field methods to define the hydraulic properties of soil, Soil Sci. Soc. Am. J., 54, 299-304, 1990. 
Comegna, A., Severino, G., and Sommella, A.: Surface measurements of hydraulic properties in an irrigated soil using a disc permeameter, WIT Trans. Ecol. Environ., 96, 341-353, 2006.

Davis, S. H., Vertessy, R. A., and Silberstein, R. P.: The sensitivity of a catchment model to soil hydraulic properties obtained by using different measurement techniques, Hydrol. Process., 13, 677-688, 1999.

Dixon, R. M.: Design and use of closed-top infiltrometers, Soil Sci. Soc. Am. Proc., 39, 755-763, 1975.

Fuentes, J. P., Flury, M., and Bezdicek, D. F.: Hydraulic properties in a silt loam soil under natural prairie, conventional till, and notill, Soil Sci. Soc. Am. J., 68, 1679-1688, 2004.

Ghafoor, A., Koestel, J., Larsbo, M., Moeys, J., and Jarvis, N. J.: Soil properties and susceptibility to preferential solute transport in tilled topsoil at the catchment scale, J. Hydrol., 492, 190-199, 2013.

Gonzalez-Sosa, E., Braud, I., Dehotin, J., Lassabatere, L., AnguloJaramillo, R., Lagouy, M., Branger, F., Jacqueminet, C., Kermadi, S., and Michel, K.: Impact of land use on the hydraulic properties of the topsoil in a small French catchment, Hydrol. Process., 24, 2382-2399, 2010.

Hu, W., Shao, M. A., and Si, B. C.: Seasonal changes in surface bulk density and saturated hydraulic conductivity of natural landscapes, Eur. J. Soil Sci., 63, 820-830, 2012.

Jacques, D., Mohanty, B. P., and Feyen, J.: Comparison of alternative methods for deriving hydraulic properties and scaling factors from singe-disc tension infiltrometers, Water Resour. Res., 38, 1120, doi:10.1029/2001WR000595, 2002.

Jarvis, N. J.: A review of non-equilibrium water flow and solute transport in soil macropores: principles, controlling factors and consequences for water quality, Eur. J. Soil Sci., 58, 523-546, 2007.

Jarvis, N. J.: Near-saturated hydraulic properties of macroporous soils, Vadose Zone J., 7, 1256-1264, 2008.

Jarvis, N. J. and Messing, I.: Near-saturated hydraulic conductivity in soils of contrasting texture measured by tension infiltrometers, Soil Sci. Soc. Am. J., 59, 27-34, 1995.

Jarvis, N. J., Zavattaro, L., Rajkai, K., Reynolds, W. D., Olsen, P. A., McGechan, M., Mecke, M., Mohanty, B., Leeds-Harrison, P. B., and Jacques, D.: Indirect estimation of near-saturated hydraulic conductivity from readily available soil information, Geoderma, 108, 1-17, 2002.

Klute, A. and Dirksen, C.: Hydraulic conductivity and diffusivity: laboratory methods, in: Methods of soil analysis Part 1-Physical and mineralogical methods, edited by: Klute, A., ASA/SSSAJ, Madison WI, USA, 687-734, 1986.

Lilly, A., Nemes, A., Rawls, W. J., and Pachepsky, Y. A.: Probabilistic approach to the identification of input variables to estimate hydraulic conductivity, Soil Sci. Soc. Am. J., 72, 16-24, 2008.

Lin, H.: Earth's Critical Zone and hydropedology: concepts, characteristics, and advances, Hydrol. Earth Syst. Sci., 14, 25-45, doi:10.5194/hess-14-25-2010, 2010.

Lin, H. S., McInnes, K. J., Wilding, L. P., and Hallmark, C. T.: Effects of soil morphology on hydraulic properties. II. Hydraulic pedotransfer functions, Soil Sci. Soc. Am. J., 63, 955-961, 1999.

Logsdon, S. D. and Jaynes, D. B.: Methodology for determining hydraulic conductivity with tension infiltrometers, Soil Sci. Soc. Am. J., 57, 1426-1431, 1993.
Mallants, D., Mohanty, B. P., Jacques, D., and Feyen, J.: Spatial variability of hydraulic properties in a multi-layered soil profile, Soil Sci., 161, 167-181, 1996.

McKenzie, N. J. and Jacquier, D. W.: Improving the field estimation of saturated hydraulic conductivity in soil survey, Austr. J. Soil Res., 35, 803-825, 1997.

Moosavi, A. A. and Sepaskhah, A.: Artificial neural networks for predicting unsaturated soil hydraulic characteristics at different applied tensions, Arch. Agron. Soil Sci., 58, 125-153, 2012.

National Research Council (NRC): Basic research opportunities in earth science, National Academy Press, Washington D.C., USA, 2001.

Nemes, A., Schaap, M. G., Leij, F. J., and Wösten, J. H. M.: Description of the unsaturated soil hydraulic database UNSODA version 2.0, J. Hydrol., 251, 151-162, 2001.

Nemes, A., Rawls, W. J., and Pachepsky, Y. A.: Influence of organic matter on the estimation of saturated hydraulic conductivity, Soil Sci. Soc. Am. J., 69, 1330-1337, 2005.

Reynolds, W. D.: Tension infiltrometer measurements: implications of pressure head offset due to contact sand, Vadose Zone J., 5, 1287-1292, 2006.

Reynolds, W. D. and Elrick, D. E.: Determination of hydraulic conductivity using a tension infiltrometer, Soil Sci. Soc. Am. J., 55, 633-639, 1991.

Schaap, M. G. and Leij, F. J.: Improved prediction of unsaturated hydraulic conductivity with the Mualem-van Genuchten model, Soil Sci. Soc. Am. J., 64, 843-851, 2000.

Schaap, M. G., Leij, F. J., and van Genuchten, M. T.: ROSETTA: a computer program for estimating soil hydraulic parameters with hierarchical pedotransfer functions, J. Hydrol., 251, 163-176, 2001.

Shouse, P. J. and Mohanty, B. P.: Scaling of near-saturated hydraulic conductivity measured using disc infiltrometers, Water Resour. Res., 34, 1195-1205, 1998.

Smettem, K. R. J. and Clothier, B. E.: Measuring unsaturated sorptivity and hydraulic conductivity using multiple disc permeameters, J. Soil Sci., 40, 563-568, 1989.

Špongrová, K., Kechavarzi, C., Dresser, M., Matula, S., and Godwin, R.J.: Development of an automated tension infiltrometer for field use, Vadose Zone J., 8, 810-817, 2009.

Thompson, S. Harman, C. J., Heine, P., and Katul, G. G.: Vegetation-infiltration relationships across climatic and soiltype gradients, J. Geophys. Res.-Biogeosci., 115, G02023, doi:10.1029/2009JG001134, 2010.

Vandervaere, J.-P., Vauclin, M., and Elrick, D. E.: Transient flow from tension infiltrometers. II. Four methods to determine sorptivity and conductivity, Soil Sci. Soc. Am. J., 64, 1272-1284, 2000.

Van Genuchten, M. T.: A closed form equation for predicting the hydraulic conductivity of unsaturated soils, Soil Sci. Soc. Am. J., 44, 892-898, 1980.

Ventrella, D., Losavio, N., Vonella, A. V., and Leij, F. J.: Estimating hydraulic conductivity of a fine-textured soil using tension infiltrometry, Geoderma, 124, 267-277, 2005.

Vereecken, H., Weynants, M., Javaux, M., Pachepsky, Y., Schaap, M. G., and van Genuchten, M. T.: Using pedotransfer functions to estimate the van Genuchten-Mualem soil hydraulic properties: a review, Vadose Zone J., 9, 795-820, 2010. 
Wang, T., Wedin, D., and Zlotnik, V. A.: Field evidence of a negative correlation between saturated hydraulic conductivity and soil carbon in a sandy soil, Water Resour. Res., 45, W07503, doi:10.1029/2008WR006865, 2009.

Wang, Y. Q., Shao, M. A, Liu, Z. P., and Horton, R.: Regional-scale variation and distribution patterns of soil saturated hydraulic conductivities in surface and subsurface layers in the loessial soils of China, J. Hydrol., 487, 13-23, 2013.

Watson, K. W. and Luxmoore, R. J.: Estimating macroporosity in a forest watershed by use of a tension infiltrometer, Soil Sci. Soc. Am. J., 50, 578-582, 1986.

Whitbread, A. M., Blair, G. J., and Lefroy, R. D. B.: Managing legume leys, residues and fertilisers to enhance the sustainability of wheat cropping systems in Australia 2. Soil physical fertility and carbon, Soil Till. Res., 54, 77-89, 2000.
White, I. Sully, M. J., and Perroux, K. M.: Measurement of surfacesoil hydraulic properties: disc permeameter, tension infiltrometers and other techniques, in: SSSA Special Publ. 30, edited by: Topp, G. C., Reynolds, W. D., and Green R. E., 69-103, Madison, WI, USA, 1992.

Wösten, J. H. M., Pachepsky, Y. A., and Rawls, W. J.: Development and use of a database of hydraulic properties of European soils, Geoderma, 90, 169-185, 1999.

Wösten, J. H. M., Lilly, A., Nemes, A., and le Bas, C.: Pedotransfer functions: bridging the gap between available basic soil data and missing soil hydraulic characteristics, J. Hydrol., 251, 123-150, 2001.

Zhou, X., Lin, H.S., and White, E. A.: Surface soil hydraulic properties in four soil series under different land uses and their temporal changes, Catena, 73, 180-188, 2008. 